\title{
A Preliminary Study of the Effects of a Comprehensive Teaching Program, Based on Questioning, to Improve Tactical Actions in Young Footballers
}

Perceptual and Motor Skills

$0(0) 1-15$

(C) The Author(s) 2016

Reprints and permissions: sagepub.com/journalsPermissions.nav DOI: $10.1177 / 0031512516649716$ pms.sagepub.com

@SAGE

\section{Alba Práxedes and Alberto Moreno \\ Faculty of Sport Sciences, University of Extremadura, Cáceres, Spain}

\section{Javier Sevil and Luis García-González}

Faculty of Health and Sport Sciences, University of Zaragoza, Huesca, Spain

\section{Fernando Del Villar}

Faculty of Sport Sciences, University of Extremadura, Cáceres, Spain

\begin{abstract}
The aim of this study was to analyze the effect of a comprehensive teaching program, based on questioning on decision making, and execution in football. The intervention program, based on teaching games for understanding model and including the application of questioning in a context of modified games, was applied during $2 \mathrm{I}$ training sessions. A quasi-experimental study with a prepost design with 18 male football players $(M=10.7$ years, $S D=0.6)$ was developed over 18 weeks. Participants were divided into experimental group $(n=9)$ and control group $(n=9)$. A total of 1532 actions were observed (II20 passes and $4 \mid 2$ dribbling). Results showed that after applying the intervention program, the players in the experimental group showed better decision making in the pass and dribbling actions, and better execution in the pass action, compared with the players from the control group. These results suggest
\end{abstract}

\section{Corresponding Author:}

Alba Práxedes, Faculty of Sport Sciences, University of Extremadura, Av. Universidad s/n, Cáceres 10003, Spain.

Email: apraxede@alumnos.unex.es 
that the application of questioning in a context of modified games must be taken into account to promote tactical training in young footballers and to improve their tactical behavior.

\section{Keywords}

questioning, cognitive processes, teaching games for understanding, youth

\section{Introduction}

In team sports, where there is a prevalence of open skills, such as football, there is constant uncertainty in the game environment where the athlete develops the cognitive process of decision making or response selection (García-González, Moreno, Moreno, Iglesias, \& Del Villar, 2009). From the perspective of cognitive psychology, the study of decision making focuses mainly on the reasoning processes and on the thoughts linked to decision making that a player develops in competition, which includes the procedural knowledge that the player has about the sport, for example, offensive and defensive game patterns or previous experiences and competitions (García-González, Moreno, Gil, Moreno, \& Del Villar, 2014).

Based on the fact that these tactical-decisional skills and cognitive skills can be trained (Vickers, Reeves, Chambers, \& Martell, 2004), the activities to develop them are therefore essential. Thus, to develop tactical-decision making and cognitive skills in sport, the greatest possible number of tactical experiences must be promoted and constructed (García-González, Moreno, Moreno, Gil, \& Del Villar, 2013), with a prevalence of decision training over behavioral training (Vickers, 2007). Griffin, Brooker, and Patton (2005) indicated the "Teaching Games for Understanding (TGfU)" model developed by Bunker and Thorpe (1982) as one of the methodologies that most favors athletes' decision-making capacity. The objective of this model, based on the pedagogical principles of modified games (modified game through representation and modified game through exaggeration) and on questioning, is to understand the game through tactical knowledge (Gray, \& Sproule, 2011). Both methodological tools are central to the pedagogy of a Game Sense approach.

Based on this proposal, the modified game always allows the contents to be learned in a tactical real game situation, where the player is at the center of the learning process, repositioning the role of the coach to that of a facilitator (Dyson, Griffin, \& Hastie, 2004). Specifically, modified games are played on reduced pitch areas, using adapted rules and involving a smaller number of players (Hill-Haas, Dawson, Impellizzeri, \& Coutts, 2011). In this sense, Gutiérrez, Fisette, García-López, and Contreras (2014) indicated the importance of cognitive aspects for game performance and of the need to bear in mind different tactical contexts. However, in youth football, the subject of this 
study, there are a limited number of studies that directly or indirectly analyze the effect of the use of the modified game as a methodological resource (Blomqvist, Vänttinen, \& Luhtanen, 2005).

Lorains, Ball, and MacMahon (2013) pointed out the need to use representative tasks to engage athletes and make them feel like they are making decisions in a real game situation. Moreover, to assess the effectiveness of an intervention, in situ conditions must be used, where athletes are required to perform real sporting actions, because the effects of expertise are more apparent under these conditions (Travassos et al., 2013).

Regarding questioning, a basic and essential aspect of the TGfU model, Thorpe, Bunker, and Almond (1986) point out that this is also a methodological tool that develops knowledge of game tactical skills. This technique consists in asking the player a series of questions that explore the critical dimension required to effectively execute a technical-tactical skill. Therefore, this process requires coaches not to tell players the execution pattern that they have to carry out but, instead, to ask the players to analyze their own tactical responses during the execution of the tasks, based on the key points present in the training situation (Vickers, 2007).

Raab and Johnson (2007) point out that questioning is a tool that can obtain improvements in highly complex situations and that it permits directing the athletes' attention toward specific aspects, obtaining positive results (Vickers, 2007). In this sense, Gréhaigne, Richard, and Griffin (2005) point out the need to apply effective questioning to favor cognitive development and thus create a critical and reflexive attitude in the athlete, focusing attention on learning the what, the why, and the when of a technical-tactical behavior (Bunker \& Thorpe, 1982). Furthermore, it must be highlighted that questioning is a tool that has given rise to improvements in decision training (García-González et al., 2013), finding favorable results not only in the decision and tactical variables in open type sports but also in the motor execution of a technical skill (Gil \& Del Villar, 2014). Thus, questioning contributes to greater development of cognitive expertise (Gil-Arias, Del Villar, García-González, Moreno, \& Moreno, 2015).

Likewise, some of the intervention programs used are based on explicit learning (e.g. Raab, 2003). In this sense, the coach does not use a controlling style, telling the players how to act. Instead, the coach asks questions about what to do and how, with respect to tactical complexity tasks, where the complexity is adapted to the athletes' execution level (modified games) by manipulating the task constraints.

The research presented is a continuation of in-depth study of tactical action in youth sport, by applying a comprehensive teaching program based on questioning among young football players learning pass and dribbling skills.

Hypothesis 1. Players who participated in the intervention program would significantly improve their decision making in comparison to players from the control group. 
Hypothesis 2. Players who participated in the intervention program would significantly improve their execution in comparison to players from the control group.

\section{Method}

\section{Participants}

The study sample comprised 18 young football players, with ages between 10 and 12 years $(M=10.7, S D=0.6)$ and with experience in a Spanish youth football league of between 3 and 6 years (experimental group: $M=4.9$ years, $S D=0.8$; control group: $M=4.8$ years, $S D=0.1)$. The experimental group and the control group were each made up of nine players, respectively, who belonged to two different teams from the same club with the same level of competition (U12). Both the experimental team and the control team coaches had one year's experience in charge of a team (the first year as a coach was also in a team with youth players).

To guarantee the equity of the groups and prior to applying the intervention program with the experimental group, a homogeneity analysis was performed of the variances using Levene's test. It was verified that the groups were equivalent on decision-making skills (pass: Levene statistic $=.97, p=.33$; dribbling: Levene statistic $=1.10, p=.30$ ) and pass execution skills (pass: Levene statistic $=.91$, $p=.34$; dribbling: Levene statistic $=.13, p=.73$ ).

The research was carried out under the recommendations of the Declaration of Helsinki and was approved by the Research Ethics Committee of the University of Extremadura. Both participants and parents were informed of the study and a consent sheet had to be signed.

\section{Variables}

The comprehensive teaching program was identified as the independent variable. In order to guarantee the correct application of the comprehensive teaching model (TGfU), the experimental group coach was instructed by an expert who had at least eight years' experience in football and who was also highly qualified in Sport and Exercise Science in Spain. As in the study by Harvey, Cushion, Wegis, and Massa-Gonzalez (2010), the training program was developed over three sessions, each one lasting for one and a half hours. In the first session, the basic principles of the TGfU model were addressed; in the second session, emphasis was placed on the application of modified games; and the last session addressed the use of questioning in the formation of young footballers. The coach and the researcher prepared the sessions prior to each intervention. To ensure that the model was correctly applied (Hastie \& Cassey, 2014), the sessions were supervised by a researcher with more than 
eight years' experience supervising coaches. The supervisor also attended the training sessions.

In this research, the comprehensive teaching program based on questioning, which was applied for 21 training sessions, took place within a context of modified games. Therefore, in the TGfU practice started within the context of a real game. In each training session and after a 2-minute low intensity warm-up, four tasks lasting for 15 minutes each and with a high tactical component were carried out. More specifically, each modified game focused on one of Bayer's tactical attack principles (1992), e.g. keeping possession of the ball, advancing toward the opposite goal and shooting with the least opposition level. Task constraints were based on two pedagogical principles known as representation (e.g. 4 vs. 4 in half the 7 -football field) and exaggeration (e.g. 3 vs. 2 where the objective was to score in one of the goals located on the baseline). Thus, the application of modified games aimed to provide greater practice variability and thus create greater uncertainty. One question was prepared for each task.

Within this context of modified games, the application of the questioning aimed to involve the player cognitively, which would require a greater selection capacity and to a certain extent benefit the quality of decision making. Following the three phases indicated by Vickers (2007), the protocol presented later was designed: (1) Questions were focused on a tactical concept to be dealt with during each task (e.g. in a situation of 3 vs. 2 in which the objective was to attack the opposite goal with lower opposition level, the question was which teammate did you decide to pass to?); (2) After asking the question, there was a pause to let the football player think and prepare his own answer; (3) After ending the task, the players discussed the application of the tactical concept dealt with for a maximum of 2 minutes; and (4) Additionally, the coach asked personalized questions to those players who did not solve the task.

The control group carried out its training sessions according to a traditional methodology and with the same structure as the experimental groups (four tasks of 15 minutes each). The coach designed tasks with a technical approach that differed from real game situations, in the majority of the occasions without opposition. Furthermore, the coach did not ask the players any type of question, simply establishing explicative and prescriptive feedback about the task.

The dependent variables were decision making and execution.

Decision making was measured as the percentage of correct decisions. The number of appropriate and inappropriate pass and dribbling actions were recorded, from the decision viewpoint, using the Game Performance Evaluation Tool (GPET; García-López, González-Víllora, Gutiérrez, \& Serra, 2013), considering the decision-making category for this. The final percentage values of adequate decisions, for each player in each one of the matches played, were calculated according to the following formula: number of adequate decisions/ total decisions. 
Execution was measured as the percentage of adequate executions. The number of appropriate and inappropriate pass and dribbling actions were recorded, from the execution viewpoint, using the GPET (García-López et al., 2013), considering the execution category for this. The final percentage values of adequate executions, for each player in each one of the matches played, were calculated according to the following formula: number of adequate executions/ total executions.

\section{Measures}

Systematic observation was used as a data compilation instrument to measure decision making and execution (González-Víllora, García-López, Pastor, \& Contreras, 2011; Harvey et al., 2010) for the pass and dribbling actions. In the current study, the GPET (García-López et al., 2013), a specific instrument in football, was used to observe this parameter, offering the possibility of evaluating both the role of the player with the ball and the role of the player without the ball. This instrument has been used before in young footballers (e.g. Gutiérrez et al., 2014), and it is based on the original instrument of French and Thomas (1987). It permits evaluating both measures in real game situations, as recommended by Travassos et al. (2013).

All the pass and dribbling actions of each one of the players on the team, both in the control group and in the experimental group, were recorded. To evaluate decision making, the decision-making component of this instrument was used, assigning a value of 1 to appropriate decisions or successful executions and 0 to inappropriate decisions or unsuccessful executions. Coding procedures are described in Tables 1 and 2.

A total of 1532 actions were observed (1 120 passes and 412 dribbling), corresponding to the first three and the last three matches of the Extremadura (Spain) football league of the 2013 or 2014 season. The following audiovisual and technological means were used to develop this research: a SONY VAIO laptop computer, a Sony HDRXR155 video camera, a recording angle conversion lens $(\times 0.75)$ : VCL-HGA07B, a Hama Gamma Series tripod, and the SPSS 19.0 software for statistical data.

\section{Reliability in the Observation of Decision Making and Execution}

An observer, unaware of the investigation, was trained to analyze decision making and the execution of the pass and dribbling actions. He was trained by an expert with football knowledge (Level I in the Spanish Football Federation) and with experience in observational methodology (researcher with experience in research project management). A sample of more than $10 \%$ of the total was used during the training. Cohen's kappa coefficient was used for the intraobserver reliability analysis, obtaining values of over .90 in the last four 
Table I. GPET coding procedures for decision making (soccer; García-López et al., 20I3).

Decision making
Passing
Passing to a teammate who is unmarked.
sive player in a position to cut off the pass.
Passing to an area of the pitch where no teammate is
positioned.
Taking the ball upfield, whilst not closely marked, to a free
space.
An appropriate change of direction away from a defender (right
or left) to an open area of the pitch.
The player advances by positioning his body between the
opponent and the ball in order to protect the ball.
The player does not move and protects the ball with his body
when the defender pressures him and does not have the
option of attacking.
Charging.
Dribbling when there is an unmarked teammate in a better
position.
A player running with the ball at his feet when an opponent is
close and has a very good chance of winning the ball.
A player running with the ball at his feet when an opponent is
close and not protecting the ball with the body.
Dribbling away from the goal, dribbling with the ball without
going forward or attacking the defense.
The player does not move and does not protect the ball with
his body when the defender pressures him and does not
have the option of attacking.

GPET: Game Performance Evaluation Tool.

training sessions, thus exceeding .81, which is the minimum value required to consider adequate concordance (Fleiss, Levi, \& Cho Paik, 2003). Therefore, the necessary reliability for the later dependent variable encoding was obtained. For the time reliability analysis of the measurement, the same encoding was developed at two different moments, with a time difference of 10 days, obtaining Cohen's kappa values of over .85 .

\section{Procedures}

This was a quasi-experimental study with a prepost design and two natural groups belonging to real teams. Three research phases were established to assess the intervention program. 
Table 2. GPET coding procedures for execution (soccer; García-López et al., 2013).

\begin{tabular}{lll}
\hline Execution & Successful pass to a teammate: To his body if he is sta- \\
tionary, lead pass if he is running. \\
Appropriate length and speed. \\
Interception. \\
Pass is too hard. \\
Out of play. \\
Pass is too far behind or in front of a teammate. \\
Successfully attacking with the ball. \\
Loss of control. \\
Loss of ball due to legal challenge. \\
Commits a foul (offensive foul).
\end{tabular}

GPET: game performance evaluation tool.

Preintervention. First, to establish the initial level prior to the intervention, the different values of the game action (decision making and execution) were recorded and registered. These were obtained by the players in the three matches corresponding to the first three league games.

Application of the intervention program. This was comprised a total of 21 training sessions, during which the comprehensive teaching program, based on questioning, was applied between the pre- and postmeasurements. Two weekly sessions were held, each one lasting for 1 hour. During this phase (lasting for 12 weeks), the different meetings to supervise the design of each one of the sessions with the correct application of questioning were held, taking place the day before. A follow-up and a detailed observation of the development of the training sessions were carried out to guarantee that the intervention program was being implemented correctly.

Postintervention. To know the effect of applying the intervention program, the last three league matches, corresponding to the regular league, were recorded and registered, thus completing the recording of matches and subsequent observation of decision making and execution.

\section{Statistical Analysis}

The SPSS 19.0 statistical program was used to analyze and process the data. Data normality was examined through the Shapiro-Wilk test and the homogeneity of variance through Levene's test, as a prior stage to the application of the 
intervention program. The assessment of both statistics made it possible to use parametric statistics, determining that the groups were equivalent in all study variables.

To do so, for the decision making and execution variables, an inferential analysis was performed through a two-factor multi variate analysis of variance with repeated measures in one factor in order to determine the effect on the interaction between the two measurement moments (preintervention and postintervention) and between the two groups (experimental and control). The partial eta-squared statistic was used $\left(\eta_{p}^{2}\right)$ as the effect size.

\section{Results}

Results showed an interaction effect between test-time (preintervention and postintervention) and group (control and experimental) factors, and a medium effect size in decision making and execution skills, Wilks' Lambda $=0.69$; $\left.F(4,34)=3.88, p=.01, \eta_{p}^{2}=0.031\right)$. The univariate analysis shows us that, in the pretest, there are no significant differences between the control group and the experimental group in any other variables studied. With respect to decision making, Table 3 shows the comparisons by pairs in each one of the study phases. In the posttreatment measurement, significant differences were found between both groups in the pass and dribbling actions.

With respect to execution, Table 4 shows the comparisons by pairs in each one of the study phases. In the posttreatment measurement, significant differences were found between both groups in the pass action. This did not occur for the dribbling action.

Table 3. Descriptive statistics and pairwise comparison of decision-making skills for pretest and posttest.

\begin{tabular}{|c|c|c|c|c|c|c|c|c|c|c|c|}
\hline \multirow{2}{*}{$\begin{array}{l}\text { Decision- } \\
\text { making } \\
\text { skills }\end{array}$} & \multirow[b]{2}{*}{$\begin{array}{l}\text { Test } \\
\text { time }\end{array}$} & \multicolumn{2}{|c|}{$\begin{array}{c}(\mathrm{I}) \\
\text { Experimental }\end{array}$} & \multicolumn{2}{|c|}{$\begin{array}{c}(\mathrm{J}) \\
\text { Control }\end{array}$} & \multirow{2}{*}{$\begin{array}{c}\text { Mean } \\
\text { difference } \\
(I-J)\end{array}$} & \multirow[b]{2}{*}{$\begin{array}{l}\text { Typical } \\
\text { error }\end{array}$} & \multirow[b]{2}{*}{$p$} & \multirow[b]{2}{*}{$\eta_{p}^{2}$} & \multicolumn{2}{|c|}{$\begin{array}{c}\text { Differences } \\
95 \% \mathrm{Cl}\end{array}$} \\
\hline & & $M$ & $S D$ & $M$ & $S D$ & & & & & UL & LL \\
\hline \multirow[t]{2}{*}{ Pass } & Pre & .75 & .15 & .76 & .15 & -.004 & .05 & .93 & 0.00 & -.10 & .09 \\
\hline & Post & .85 & .14 & .64 & .23 & .21 & .06 & .001 & 0.25 & .09 & .34 \\
\hline \multirow[t]{2}{*}{ Dribbling } & Pre & .81 & .18 & .78 & .22 & .03 & .07 & .69 & 0.004 & -.11 & .16 \\
\hline & Post & .95 & .12 & .73 & .31 & .22 & .08 & .008 & 0.17 & .06 & .38 \\
\hline
\end{tabular}

Pre: pretest phase; Post: posttest phase; Cl: confidence interval; LL: lower limit; UL: upper limit. 
Table 4. Descriptive statistics and pairwise comparison of execution skills for pretest and posttest.

\begin{tabular}{|c|c|c|c|c|c|c|c|c|c|c|c|}
\hline \multirow[b]{2}{*}{$\begin{array}{l}\text { Execution } \\
\text { skills }\end{array}$} & \multirow[b]{2}{*}{$\begin{array}{l}\text { Test } \\
\text { time }\end{array}$} & \multicolumn{2}{|c|}{$\begin{array}{c}(\mathrm{I}) \\
\text { Experimental }\end{array}$} & \multicolumn{2}{|c|}{$\begin{array}{c}(J) \\
\text { Control }\end{array}$} & \multirow{2}{*}{$\begin{array}{c}\text { Mean } \\
\text { difference } \\
(I-J)\end{array}$} & \multirow[b]{2}{*}{$\begin{array}{l}\text { Typical } \\
\text { error }\end{array}$} & \multirow[b]{2}{*}{$p$} & \multirow[b]{2}{*}{$\eta_{p}^{2}$} & \multicolumn{2}{|c|}{$\begin{array}{c}\text { Differences } \\
95 \% \mathrm{Cl}\end{array}$} \\
\hline & & $M$ & $S D$ & $M$ & $S D$ & & & & & UL & LL \\
\hline \multirow[t]{2}{*}{ Pass } & Pre & .62 & .18 & .64 & .16 & -.02 & .05 & .73 & .003 & -.13 & .09 \\
\hline & Post & .72 & .13 & .55 & .27 & .17 & .07 & .02 & .14 & .03 & .32 \\
\hline \multirow[t]{2}{*}{ Dribbling } & Pre & .53 & .32 & .56 & .32 & -.03 & .10 & .79 & .002 & -.23 & .18 \\
\hline & Post & .70 & .27 & .58 & .34 & .12 & .10 & .25 & .04 & -.08 & .32 \\
\hline
\end{tabular}

Pre: pretest phase; Post: posttest phase; Cl: confidence interval; LL: lower limit; UL: upper limit.

\section{Discussion}

The main objective of this study was to analyze the effect of the application of a comprehensive teaching program, based on questioning, on decision making, and execution in the pass and dribbling technical-tactical skills on young footballers (U12). The results obtained in terms of the different hypotheses considered in the research will be discussed later.

The first hypothesis of this study established that players who participated in the intervention program would significantly improve their decision making in comparison to players from the control group. The results obtained showed significant differences between both groups in the posttreatment measurement in the pass and dribbling actions, and the mean of the experimental group was higher in both actions, compared to the control group. The results showed that the comprehensive teaching program, based on questioning, has given rise to a significant improvement in the decision capacity of the athletes from the experimental group, although not so in the players from the control group, in both the pass and dribbling actions. Therefore, the comprehensive teaching program improved decision making.

In scientific literature, there are various studies that are in line with these results. In a volleyball study, Broek, Boen, Claessens, Feys, and Ceux (2011) compared three teaching methodologies (traditional, comprehensive without the involvement of questions, and comprehensive with the involvement of questions). The results showed that in the latter, the significant differences between pretest and posttest were much higher than those of the other two groups, in terms of the tactics and decision-making variables.

Authors such as García-González et al. (2014) and García-González et al. (2013) indicated the effectiveness of questioning as a tool to improve decision making. Thus, in their study, in which the decision-training program developed 
included the joint application of video feedback and questioning, favorable results were obtained in terms of decision making.

In short, related to the first hypothesis, it is relevant to point out that those players that were submitted to the intervention program to optimize the cognitive variables reached a higher level of cognitive expertise, developing a selection of more tactical responses in the attack action (Del Villar, García-González, Iglesias, Moreno, \& Cervelló, 2007; Gutiérrez, González-Víllora, García-López, \& Mitchell, 2011). Therefore, the comprehensive teaching program, based on questioning, appeared to be effective in the experimental group, giving rise to significant improvements in decision making in the pass and dribbling actions.

The second hypothesis established that players who participated in the intervention program would significantly improve their execution in comparison to players from the control group. The results showed significant differences between the two groups in the posttreatment measurement in the pass action, but not so in the dribbling action, where no differences were found. The results obtained showed that the intervention program has not been sufficiently effective to improve the execution variable, in the dribbling action. Therefore, the comprehensive teaching program may not improve this variable. It is important to emphasize that the program was focused on the tactical role of the players and not on other factors in performance, such as technical, physiological, and emotional variables (Phillips, Davids, Renshaw, \& Portus, 2010). This fact favored the lack of significant differences in the execution variable. In this regard, there are studies that have not found significant differences in execution but have found them in decision making, after applying a technical-tactical teaching model (comprehensive teaching; Gutiérrez \& García-López, 2012; Turner \& Martinek, 1992). In youth football, in order for there to be an improvement in the execution skill in a real game context, emphasis must be placed during training not only just on cognitive variables (knowledge and decision making) but also on the technical content of the game action, especially when the young players present considerable technical limitations.

In relation to the differences obtained in the two game actions studied, in which there have been improvements in the execution of the pass, but not in dribbling, the improvements obtained may differ depending on the different actions. Thus, in the pass skill, there was a linear relationship between decision making and execution (Del Villar et al., 2007; García-González et al., 2014; Hastie, Sinelnikov, \& Guarino, 2009; Vickers et al., 2004). However, this relationship does not exist in the dribbling skill, as noted in the study by GonzálezVíllora et al. (2011), where the results showed that football players had more limitations in some technical-tactical contents than others, e.g. the feint, an essential element for dribbling. There are studies in both the physical education context (Blomqvist et al., 2005; Gutiérrez \& García-López, 2012) and in the sport context (Robinson, Foran, \& Francis, 2011) that have obtained significant differences for the dribbling variable. The differences between the different 
research studies are probably due to the fact that the initial level of the sample of each study was quite varied with respect to each technical-tactical action.

Related to the second hypothesis, the comprehensive teaching program was effective with youth footballers in improving the game execution, but only in terms of the pass action. A comprehensive teaching program must start at the athletes' initial level and later adjust the content of each game action in an individual manner. Likewise, it is necessary to place emphasis during training not only on the cognitive variables (knowledge and decision making) but also on the technical content of the game action, especially when these young players present considerable technical limitations.

Based on these results, the coach's role in learning tasks with tactical complexity should be examined, given that he/she must reach a new dimension as a mediator between the athlete and the task. This favors explicit learning, through the coach's direct interventions, which involves asking the athletes questions to make them reflect and analyze tactical possibilities, in representative game situations (Memmert \& Roth, 2007). However, the coach must also favor the athlete's implicit learning, given that in low tactical complexity situations the intuitive response is more effective in learning to decide (Raab, 2003). Thus, when planning decisionbased training, variable practice moments, where the coach manipulates the task constraints to favor the athlete's intuitive and adaptive behaviors, must be combined with deliberative and explicit analysis moments, to understand the tactical principles that explain the effective behavior in the game action.

Finally, and due to the sample size, further research studies needed to establish more conclusive results. Thus, it will also be necessary to study the application of these programs with a larger number of players, and in turn, on players of different ages, and different levels of sport expertise in order to generate knowledge and make the coaches' work easier, providing new coaching methods.

\section{Declaration of Conflicting Interests}

The author(s) declared no potential conflicts of interest with respect to the research, authorship, and/or publication of this article.

\section{Funding}

The author(s) received no financial support for the research, authorship, and/or publication of this article.

\section{References}

Blomqvist, M., Vänttinen, T., \& Luhtanen, P. (2005). Assessment of secondary school students' decision-making and game-play ability in soccer. Physical Education and Sport Pedagogy, 10, 107-119.

Broek, G., Boen, F., Claessens, M., Feys, J., \& Ceux, T. (2011). Comparison of three instructional approaches to enhance tactical knowledge in volleyball among university students. Journal of Teaching and Physical Education, 30, 375-392. 
Bunker, D., \& Thorpe, R. (1982). A model for the teaching of games in secondary schools. Bulletin of Physical Education, 18, 5-8.

Del Villar, F., García-González, L., Iglesias, D., Moreno, M. P., \& Cervelló, E. M. (2007). Expert-novice differences in cognitive and execution skills during tennis competition. Perceptual and Motor Skills, 104, 355-365.

Dyson, B., Griffin, L. L., \& Hastie, P. A. (2004). Sport education, tactical games, and cooperative learning: Theoretical and pedagogical considerations. Quest, 56(2), 226-240.

Fleiss, J. L., Levi, B., \& Cho Paik, M. (2003). Statistical methods for rates and proportions (3rd ed.). New York, NY: Wiley.

French, K., \& Thomas, J. (1987). The relation of knowledge development to children's basketball performance. Journal of Sport Psychology, 9, 15-32.

García-González, L., Moreno, A., Gil, A., Moreno, M. P., \& del Villar, F. (2014). Effects of decision training on decision making and performance in young tennis players: An applied research. Journal of Applied Sport Psychology, 26, 426-440.

García-González, L., Moreno, M. P., Moreno, A., Gil, A., \& del Villar, F. (2013). Effectiveness of a video-feedback and questioning programme to develop cognitive expertise in sport. PLoS One, 8, e82270.

García-González, L., Moreno, M. P., Moreno, A., Iglesias, D., \& del Villar, F. (2009). Estudio de la relación entre conocimiento y toma de decisiones en jugadores de tenis, y su influencia en la pericia deportiva [Relation between knowledge and decision making in tennis players and its influence in sport expertise]. International Journal of Sport Sciences, 17, 60-75.

García-López, L. M., González-Víllora, S., Gutiérrez, D., \& Serra, J. (2013). Development and validation of the Game Performance Evaluation Tool (GPET) in soccer. Sport TK. Revista Euroamericana de Ciencias Del Deporte, 2, 89-99.

Gil, A., \& del Villar, F. (2014). Aplicación de un programa de entrenamiento decisional, en tiempo real de juego, para la mejora de rendimiento táctico individual del deportista [Application of a decision making programme, in real-time game, to improve the athlete tactical performance]. In L. García-González \& F. del Villar (Eds.), Entrenamiento táctico y decisional en el deporte (pp. 132-146). Madrid, Spain: Síntesis.

Gil-Arias, A., del Villar, F., García-González, L., Moreno, A., \& Moreno, M. P. (2015). Effectiveness of video feedback and interactive questioning in improving tactical knowledge in volleyball. Perceptual and Motor Skills, 121(3), 635-653.

González-Víllora, S., García-López, L. M., Pastor, J. C., \& Contreras, O. R. (2011). Tactical awareness and decision making in youth soccer player (10 years). Revista de Psicología del Deporte, 20, 79-97.

Gray, S., \& Sproule, J. (2011). Developing pupils' performance in team invasion games. Physical Education and Sport Pedagogy, 16, 15-32.

Gréhaigne, J. F., Richard, J., \& Griffin, L. (2005). Teaching and learning team sports and games. New York, NY: Routledge Falmer.

Griffin, L. L, Brooker, R., \& Patton, K. (2005). Working towards legitimacy: Two decades of teaching games for understanding. Physical Education and Sport Pedagogy, 10, 213-223.

Gutiérrez, D., Fisette, J., García-López, L. M., \& Contreras, O. (2014). Assessment of secondary school students' came performance related to tactical contexts. Journal of Human Kinetic, 42, 223-234. 
Gutiérrez, D., \& García-López, L. M. (2012). Assessment of primary school students' decision-making related to tactical contexts. Journal of New Approach Education Research, 1, 7-12.

Gutiérrez, D., González-Víllora, S., García-López, L. M., \& Mitchell, S. (2011). Differences in decision-making development between expert and novice invasion game players. Perceptual and Motor Skills, 112, 871-888.

Harvey, S., Cushion, C. J., Wegis, H. M., \& Massa-Gonzalez, A. N. (2010). Teaching games for understanding in American high-school soccer: A quantitative data analysis using the game performance assessment instrument. Physical Education and Sport Pedagogy, 15, 29-54.

Hastie, P. A., \& Casey, A. (2014). Fidelity in models-based practice research in sport pedagogy: A guide for future investigations. Journal of Teaching and Physical Education, 33, 422-431.

Hastie, P. A., Sinelnikov, O. A., \& Guarino, A. J. (2009). The development of skill and tactical competencies during a season of badminton. European Journal Sport Sciences, 9, 133-140.

Hill-Haas, S., Dawson, B., Impellizzeri, F. M., \& Coutts, A. J. (2011). Physiology of small-sided games training in football: A systematic review. Sports Medicine, 41(3), 199-220.

Lorains, M., Ball, K., \& MacMahon, C. (2013). Expertise differences in a video decisionmaking task: Speed influences on performance. Psychology of Sport and Exercise, 14(2), 293-297.

Memmert, D., \& Roth, K. (2007). The effects of non-specific and specific concepts on tactical creativity in team ball sports. Journal of Sports Sciences, 25(12), 1423-1432.

Phillips, E., Davids, K., Renshaw, I., \& Portus, M. (2010). Expert performance in sport and the dynamics of talent development. Sports Medicine, 40, 271-283.

Raab, M. (2003). Implicit and explicit learning of decision making in sports is affected by complexity of situation. International Journal of Sport Psychology, 34, 273-288.

Raab, M., \& Johnson, M. (2007). Implicit learning as a means to intuitive decision making in sports. In H. Plessner, T. Betsch, \& C. Betsch (Eds.), Intuition in judgment and decision making (pp. 119-134). London, England: Routledge.

Robinson, D. B., Foran, A., \& Francis, S. (2011). Pre-service physical education teachers'implementation of "TGfU tennis": Assessing elementary students'game play using the GPAI. Physical \& Health Education Nexus, 3, 1-19.

Thorpe, R., Bunker, D., \& Almond, L. (1986). Rethinking games teaching. Loughborough, England: Loughborough University of Technology.

Travassos, B., Araújo, D., Davids, K., O’Hara, K., Leitão, J., \& Cortinhas, A. (2013). Expertise effects on decision-making in sport are constrained by requisite response behaviours - A meta-analysis. Psychology of Sport and Exercise, 14, 211-219.

Turner, A., \& Martinek, T. J. (1992). A comparative analysis of two models for teaching games: Technique approach and game-centered (tactical focus) approach. International Journal of Physical Education, 29, 15-31.

Vickers, J. N. (2007). Perception, cognition, and decision training. The quiet eye in action. Champaign, IL: Human Kinetics. 
Vickers, J. N., Reeves, M. A., Chambers, K. L., \& Martell, S. (2004). Decision training. Cognitive strategies for enhancing motor performance. In A. M. Williams, \& N. J. Hodges (Eds.), Skill acquisition in sport: Research, theory and practice (pp. 103-120). London, England: Routledge.

\section{Author Biographies}

Alba Práxedes is a $\mathrm{PhD}$ student in the Faculty of Sport Sciences at the University of Extremadura, Spain. She is currently doing his doctoral thesis, which analyses the effects of an intervention program based on small-sided games in the decision making and execution, on young footballers.

Alberto Moreno is a professor in the Faculty of Sport Sciences at the University of Extremadura, Spain. His research focuses in physical education and sport contexts. Specifically, in cognitive processes, such as the decision making, in volleyball.

Javier Sevil is a PhD student in Education in the Faculty of Health and Sport Sciences at the University of Zaragoza, Spain. He is currently doing his doctoral thesis, which analyses the effects of a school-based intervention focused in autonomy support from PE teachers, parents and peers on the motivation and positive behaviors in physical education lessons and physical activity levels of adolescents.

Luis García-González is a professor in the Faculty of Health and Sport Sciences at the University of Zaragoza, Spain. His research focuses on motivation in physical education and sport context, and he also study the decision making process in sport.

Fernando Del Villar is a professor in the Faculty of Health and Sport Sciences at the University of Zaragoza, Spain. His research focuses on sport expertise: the procedural knowledge and the decision making process. He is the chef of the research group "Didactic and behavioral analysis in sport". 